\title{
Changes on Content, Structure and Surface Distribution of Lignin in Jute Fibers After Laccase Treatment
}

\author{
Aixue Dong ${ }^{\mathrm{a}, \mathrm{b}}$, Xuerong Fan ${ }^{\mathrm{a}, \mathrm{c}}$, Qiang Wang ${ }^{\mathrm{ac}}$, Yuanyuan Yu ${ }^{\mathrm{a}}$, Ping Wang ${ }^{\mathrm{a}}$, Jiugang Yuan ${ }^{\mathrm{a}}$, \\ and Artur Cavaco-Paulo ${ }^{c, d}$ \\ aKey Laboratory of Science and Technology of Eco-Textile, Ministry of Education, Jiangnan University, Wuxi, Jiangsu,

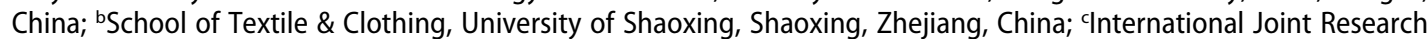 \\ Laboratory for Textile and Fiber Bioprocesses, Jiangnan University, Wuxi, Jiangsu, China; ${ }^{\mathrm{d} C e n t e r}$ of Biological \\ Engineering, University of Minho, Campus de Gualtar, Braga, Portugal
}

\begin{abstract}
Effect of laccase treatment on the content, structure, and surface distribution of lignin in jute fibers were fundamentally investigated. Four percent lignin was removed from jute fibers via the laccase treatment. The residual lignin in the laccase-treated jute fibers showed increased molecular weights, which indicated polymerization between lignins on jute fibers. Meanwhile, the phenolic hydroxyl content in lignin decreased during the laccase oxidation accompanied by demethylation of methoxyl groups and generation of carbonyl groups. Due to the degradation and subsequent polymerization of lignin by laccase, the bulgy lignins on jute fiber surfaces were redistributed, which made the surface neat and glossy.
\end{abstract}

\begin{abstract}
摘要
研究了漆酶处理对黄麻纤维中木质素含量、结构及表面分布的影响。经 漆酶处理后, 黄麻纤维中 $4 \%$ 的木质素被去除, 纤维中残余的木质素分子 量增加，表明黄麻纤维上的木质素间发生了聚合。同时木质素中酚羟基 含量降低, 并伴随着脱甲氧基作用和羰基的生成。由于漆酶作用下木质 素的降解与后续聚合, 黄麻纤维表面凸出的木质素进行了重新分配, 从 而使表面平整、光滑。
\end{abstract}

\section{KEYWORDS}

Content; distribution; jute; laccase; lignin; structure

\section{关键词}

含量; 分布; 黄麻; 漆酶; 木 质素; 结构

\section{Introduction}

Jute fiber is an abundant lignocellulosic bioresource with lignin content of 14\%-20\% and occupies the second place in the world production of natural fibers after cotton (Cao et al. 2012). It is widely used in home and industry as ropes, packing bags, carpets, papers, fiberboards, geotextiles, and reinforcements of polymer composites (Abdullah et al. 2011; Datta 2007; Ghosh et al. 2016; Jahan and Rawshan 2009). With the increasing of environmental consciousness and sustainable requirement in recent decades, natural jute fiber has shown broad developing prospects owing to its merits of low cost, abundance, renewability, and biodegradation (Mwaikambo 2006).

Recently, the emergent enzyme technology, especially the utilization of oxidoreductases, offers new approaches for the modification of lignins and lignocellulosic materials (Hüttermann et al. 2001; Liu et al. 2009; Nyanhongo et al. 2011; Sirghie et al. 2015; Sun et al. 2015b; Thakur et al. 2015; Zhou et al. 2013a). Enzymatic processes have advantages of specificity, effectness, ecofriendliness, and working under mild conditions as compared to conventional methods. Laccases (EC 1.10.3.2,

CONTACT Qiang Wang qiang_wang@163.com @ Key Laboratory of Science and Technology of Eco-Textile, Ministry of Education, Jiangnan University, Wuxi, 214122, Jiangsu, China.

Color versions of one or more of the figures in the article can be found online at www.tandfonline.com/WJNF. 
benzenediol: oxygen oxidoreductase) are the most investigated enzymes in this field. They are multicopper glycoproteins that catalyze the monoelectronic oxidation of phenols and aromatic or aliphatic amines to reactive radicals and simultaneously reduce molecular oxygen to water in a redox reaction (Riva 2006). Lignin is a three-dimensional aromatic polymer with three structural units, guaiacyl, syringyl, and p-hydroxyphenyl, linked together in an irregular manner (Del Río et al. 2009). Studies showed that lignin is a suiTable substrate for laccase and the phenolic sites of lignin macromolecules can be oxidized to phenoxyl radicals by laccase (Wong 2009). These reactive radicals can then undergo the covalent coupling to initiate the polymerization of lignins; while the degradation of lignin will occur simultaneously, mediated by the radical-induced cleavage of covalent bonds or aromatic rings. The final and most remarkable result of the lignin transformation by laccase was an increase in the molecular weight due to enhanced cross-coupling (Areskogh et al. 2010; Mattinen et al. 2008). In addition, Zhou et al. investigated the structural characteristics of sodium lignosulphonate modified by laccase, which was conducive to its adsorption and dispersion properties (Zhou et al. 2013b).

However, there are differences between the homogeneous catalysis of lignin solution and heterogeneous catalysis of lignocellulosic fibers by laccase. The surface distribution of lignin on fibers, contact of laccase with solid lignin on surface, effects of degraded lignin fragments in aqueous medium, and chemical states of residue lignin on fibers need to be considered into the laccasemediated reaction (Sealey and Ragauskas 1998b). In this work, changes of lignin in jute fibers after the treatment of laccase were fundamentally investigated in terms of content, chemical structure, and surface distribution. As far as our knowledge goes, no such comprehensive attempt has seemingly been made before.

Initially, the content of lignin in the jute fibers was determined by the sulfuric acid hydrolysis method. Then, lignins were isolated from the jute fibers by extraction with acidic dioxane/water solution and the chemical structure was characterized with gel permeation chromatography (GPC), elemental analysis, fourier transform infrared spectroscopy (FT-IR), and proton nuclear magnetic resonance spectroscopy $\left({ }^{1} \mathrm{H}-\mathrm{NMR}\right)$. Finally, the distribution of lignin on the jute fiber surface was estimated by laser scanning confocal microscope (LSCM) and scanning electron microscope (SEM). The schematic illustration of the laccase-mediated transformation and redistribution of lignins on jute fiber surfacewas showed in Figure 1.

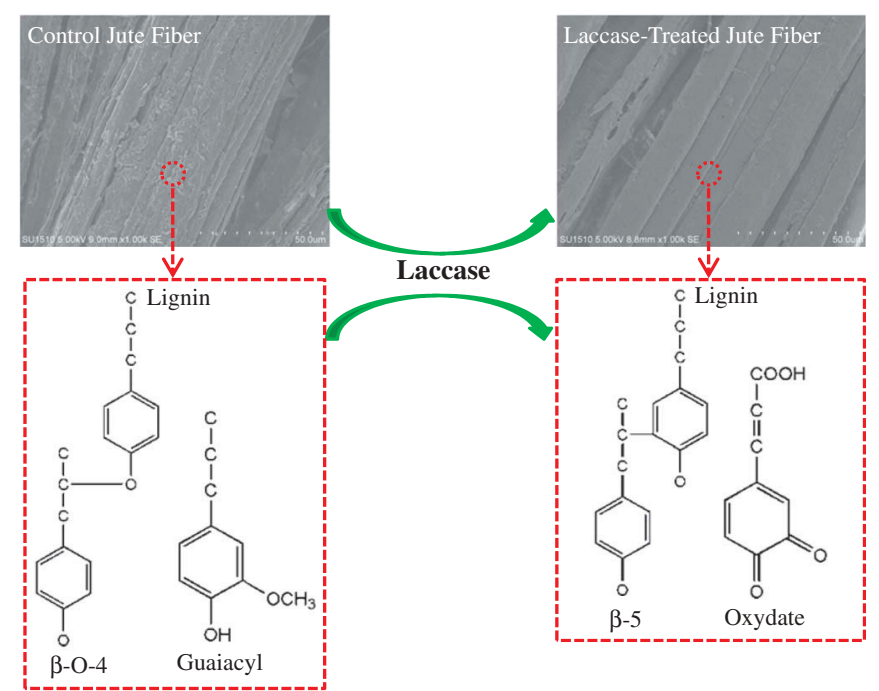

Figure 1. Schematic illustration of the laccase-mediated transformation and redistribution of lignins on jute fiber surface. 


\section{Materials and methods}

\section{Materials and Reagents}

Laccase from Trametes Versicolor and 2,2'-azino-bis-(3-ethylthiazoline-6-sulfonate) (ABTS) were provided by Sigma-Aldrich (Shanghai, China). Jute fibers were supplied by Longtai weaving Co., Ltd (Changshu, China). All the other chemicals used in the study were commercially available and of analytical purity.

\section{Laccase assay}

The activity of laccase was measured using a UV-1800 UV/Vis spectrophotometer (Shimadzu, Japan) by monitoring the oxidation of ABTS $\left(\varepsilon_{420}=36,000 \mathrm{M}^{-1} \times \mathrm{cm}^{-1}\right)$ as substrate at $420 \mathrm{~nm}$ in $\mathrm{pH} 4$ acetate buffer $(0.2 \mathrm{M})$ at $50^{\circ} \mathrm{C}$. The enzyme activity was expressed in units defined as micromoles of ABTS oxidized per minute (Childs and Bardsley 1975).

\section{Pretreatment of jute fibers}

The jute fibers were Soxhlet-extracted with benzene/ethanol (2:1, v:v) for $12 \mathrm{~h}$ to remove lipophilic extractives and then boiled with distilled water for $3 \mathrm{~h}$ to remove water-soluble fractions. As a result, the oxidation of substrate molecules by laccase and analysis of modified fibers could be carried out without interference.

\section{Treatment of jute fibers with laccase}

Jute fibers of $1 \mathrm{~g}$ were incubated in $50 \mathrm{~mL}$ acetate buffer $(\mathrm{pH} 4,0.2 \mathrm{M})$ with $2.0 \mathrm{U} / \mathrm{mL}$ laccase in a shaking bath. The reaction was allowed to proceed at $50^{\circ} \mathrm{C}$ for $4 \mathrm{~h}$. Control samples without laccase followed the same treatment conditions as mentioned above. Afterward, the jute fibers were washed with distilled water at $50^{\circ} \mathrm{C}$ for 30 min twiceand then air-dried.

\section{Determination of lignin content in jute fibers}

The lignin contents of the control and laccase-treated jute fibers were measured by the Klason method (Alves et al. 2006), which consists of sulfuric acid hydrolysis and solubilization of the carbohydrate component, leaving lignin as a residue determined gravimetrically. The removal efficiency of lignin in the jute fibers by laccase was calculated using the following equation:

$$
\text { Removal efficiency }(\%)=\frac{L c-L t}{L c \times(1-L t)} \times 100 \%,
$$

where $L_{c}$ is the lignin content of control jute fibers (\%) and $L_{t}$ is the lignin content of laccase-treated jute fibers (\%).

\section{Isolation of Lignin From Jute Fibers}

The residual lignins in the control and laccase-treated jute fibers were separated as described by Pepper et al. (1959) and purified using the method of Lundquist et al. (1977) with slight modifications.

Jute fibers of $10 \mathrm{~g}$ were ground to little flecks of 40 mesh and then refluxed with $200 \mathrm{~mL}$ dioxanewater (9:1, v:v) solution containing $0.2 \mathrm{M} \mathrm{HCl}$ at $90^{\circ} \mathrm{C}$ for $1 \mathrm{~h}$. Afterward, the mixture was filtered to separate the solid residue from the liquid phase. The obtained solid residue was washed with neutral dioxane-water (9:1, v:v) solution and then subjected to the second extraction with $200 \mathrm{~mL}$ dioxanewater $(9: 1, \mathrm{v}: \mathrm{v})$ solution containing $0.4 \mathrm{M} \mathrm{HCl}$ for $0.5 \mathrm{~h}$. The final mixture was filtered as described 
above. The two portions of the extracting and washing solutions were collected together and concentrated to about $15 \mathrm{~mL}$ on a rotary evaporator at $40^{\circ} \mathrm{C}$. Lignins were precipitated from dioxane solution by diluting into $200 \mathrm{~mL}$ cold water. The precipitate was separated by centrifugation, then washed with water three times and freeze-dried.

The crude lignins were dissolved in $35 \mathrm{~mL}$ pyridine-acetic acid-water (9:4:1, v:v:v) solution. Chloroform of $60 \mathrm{~mL}$ was added and then the mixture was stood after shaking. Afterward, the obtained substratum organic phase containing lignins was concentrated to below $25 \mathrm{~mL}$ on a rotary evaporator at $40^{\circ}$ C. The lignins were precipitated from chloroform solution by diluting into $200 \mathrm{~mL}$ roiled diethyl ether. The precipitate was separated by centrifugation, then washed with diethyl ether three times and vacuum-dried.

\section{Structure characterizations of lignins isolated from Jute fibers}

\section{Molecular mass distribution}

The molecular mass distributions of lignins isolated from control and laccase-treated jute fibers were analyzed by GPC. The GPC system used was a Waters 1515 Isocratic HPLC Pump (Waters Corporation, Milford, USA) with a Waters 2414 Refractive Index Detector (Waters Corporation, Milford, USA) and a GPC KD-802 Packed Column (Shodex, Japan).

Lignin samples were dissolved in N,N-dimethylformamide (DMF) at a concentration of $20 \mathrm{mg} /$ $\mathrm{mL}$ and an aliquot of $20 \mu \mathrm{L}$ was injected into the GPC system. The analysis was run with DMF as the eluent at a flow rate of $1.5 \mathrm{~mL} / \mathrm{min}$ and operated at a constant temperature of $35^{\circ} \mathrm{C}$. The average molecular weights of lignins were calibrated with polystyrene standards.

\section{Elemental analysis}

The carbon, hydrogen, and oxygen contents of the isolated lignins were determined on an elemental analyzer (ElementarVario EL III, Germany). The methoxyl contents were obtained from the ${ }^{1} \mathrm{H}-\mathrm{NMR}$ spectra. And the $\mathrm{C}_{9}$ formulas of lignins, $\mathrm{C}_{9} \mathrm{HxOy}\left(\mathrm{OCH}_{3}\right)_{z}$, were calculated from the carbon, hydrogen, oxygen, and methoxyl contents (Adler 1957) according to the equations below:

$$
\begin{gathered}
x=\frac{9 M_{C}}{M_{H}} \times \frac{q-\frac{3 M_{H}}{M_{\mathrm{OCH}_{3}}} \times t}{p-\frac{M_{C}}{M_{\mathrm{OCH}_{3}}} \times t}=107.232 \times \frac{q-0.097 t}{p-0.387 t}, \\
y=\frac{9 M_{C}}{M_{O}} \times \frac{s-\frac{M_{O}}{M_{\mathrm{OCH}_{3}}} \times t}{p-\frac{M_{C}}{M_{\mathrm{OCH}_{3}}} \times t}=6.756 \times \frac{s-0.516 t}{p-0.387 t}, \\
z=\frac{9 M_{C}}{M_{\mathrm{OCH}_{3}}} \times \frac{t}{p-\frac{M_{C}}{M_{\mathrm{OCH}}} \times t}=\frac{3.483 t}{p-0.387 t},
\end{gathered}
$$

where $M$ is the molar mass of elements or functional groups ( $\mathrm{g} / \mathrm{mol}), p$ is the carbon content $(\%), q$ is the hydrogen content (\%), $s$ is the oxygen content (\%), and $t$ is the methoxyl content (\%).

\section{FT-IR analysis}

The FT-IR analysis of the isolated lignins was performed using a Nicolet iS10 FT-IR spectrometer (Thermo Fisher Scientific, USA) with the $\mathrm{KBr}$ pellet technique. The spectra were recorded in the range of $4000-650 \mathrm{~cm}^{-1}$ at $4 \mathrm{~cm}^{-1}$ resolution and 16 scans per sample.

\section{${ }^{1} \mathrm{H}-\mathrm{NMR}$ analysis}

The isolated lignins were acetylated using the method of Jahan and Mun 2010. Lignin of $100 \mathrm{mg}$ was added in $10 \mathrm{~mL}$ pyridine-acetic anhydride solution (1:2, v:v) and kept for three days in dark with intermittent shaking. Then, the solution was poured into $200 \mathrm{~mL}$ roiled diethyl ether to precipitate the acetylated lignins, which were further purified by successive washing with diethyl ether and dried under vacuum. 
Then, $20 \mathrm{mg}$ acetylated lignins were dissolved in $0.45 \mathrm{~mL}$ chloroform $\left(\mathrm{CDCl}_{3}\right)$ and the proton nuclear magnetic resonance ( $\left.{ }^{1} \mathrm{H}-\mathrm{NMR}\right)$ spectra were recorded in a AVANCE $400 \mathrm{MHz}$ spectrometer (Bruker, Germany).

\section{Distribution analysis of lignin on the jute fiber surface}

The sections of the jute fibers with a thickness of $10 \mu \mathrm{m}$ were obtained by using a CM1950 freezing microtone (Lycra, Germany) with ice as the embedding agent. Then, the transverse morphology of the jute fibers and the distribution of lignin on the jute fiber sections were observed by autofluorescence without staining on a TCS SP8 confocal laser scanning microscopy (CLSM) (Lycra, Germany).

The longitudinal surfaces of the control and laccase-treated jute fibers were scanned using a SU1510 SEM (Hitachi, Japan) under $5.00 \mathrm{k}$ voltages at $1.00 \mathrm{k}$ magnification.

\section{Results and discussion}

\section{Change of lignin content in Jute fibers treated by laccase}

Table 1 showed the lignin contents of control and laccase-treated jute fibers as well as the removal efficiency of lignin by laccase. Control jute fibers had a lignin content of $13.65 \%$, while the content of lignin in jute fibers was slightly decreased to $13.17 \%$ after the laccase treatment with the lignin removal efficiency of $4.05 \%$. This is in agreement with the results reported by Sealey and Ragauskas (1998a) in the delignification of kraft pulp by laccase and laccase/mediator systems, which showed that the lignin removal efficiency by laccase, laccase/ABTS, and laccase/HBT treatments were 5\%, $35 \%$, and $55 \%$, respectively. As can be seen, the effect of laccase on the total amount of lignin in the jute fibers was weak and only a little lignin could be degraded from jute via the laccase treatment. This is mainly because of the heterogeneous catalysis and the simultaneity of polymerization and degradation on lignins by laccase. At the beginning of the laccase catalysis, some lignins were depolymerized to low-molecular-weight pieces, dissolving in the aqueous medium. In the latter stage of the reaction, with the increase of dissolved phenolic fragments in solution, the laccasemediated polymerization became predominant, and part of lignin pieces were covalently attached back to the backbone of lignin macromolecules on jute fibers (Zhou et al. 2013b). However, with the assist of some mediators such as 2,2'-azino-bis-(3-ethylthiazoline-6-sulfonate) (ABTS) and $\mathrm{N}$-hydroxybenzotriazole (HBT), the delignification by laccase can be enhanced largely.

\section{Molecular weight distribution of lignins from Jute fibers}

The molecular weight distributions of lignins isolated from control and laccase-treated jute fibers were determined by GPC method with polystyrenes as the standards. The molecular weight distribution curves were shown in Figure 2 and the various molecular weights, polydispersity of lignins were given in Table 2. After the laccase treatment of jute fibers, the molecular weight distribution curve of the separated lignin moved forward, which indicated an increase in the molecular weight. For the

Table 1. Lignin contents of the control and laccase-treated jute fibers as well as the removal efficiency of lignin in the jute fibers via the laccase treatment.

\begin{tabular}{lcc}
\hline Treatment & Lignin content in jute fibers (\%) ${ }^{\mathrm{a}}$ & Removal efficiency of lignin (\%) $^{\text {Control }}$ \\
Laccase & $13.65 \pm 0.06$ & - \\
\hline
\end{tabular}

${ }^{\mathrm{a}}$ T-test was conducted to evaluate the statistical significance of lignin content in jute fibers after laccase treatment. $a=0.05$ and two-sided test were employed. The calculated $t$ value was 4.848 , which was larger than $t_{0.05 / 2.2}(4.303)$ and indicated significant difference $(P<0.05)$ among the two lignin contents in control and laccase-treated jute fibers. 


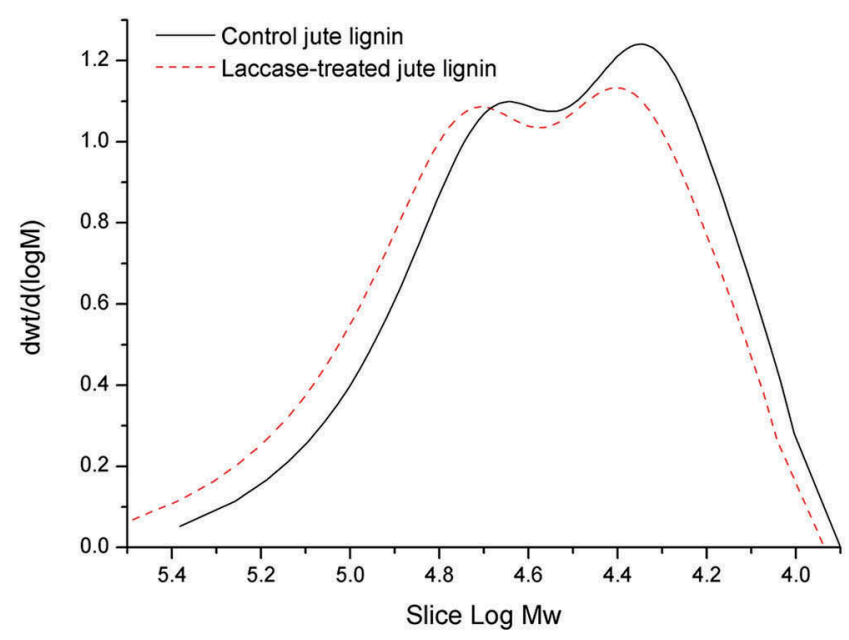

Figure 2. Molecular weight distribution curves of lignins isolated from the control and laccase-treated jute fibers.

Table 2. Weight-average molecular weight $\left(M_{w}\right)$, number-average molecular weight $\left(M_{n}\right)$, and polydispersity $\left(M_{w} / M_{n}\right)$ of lignins isolated from the controland laccase-treated jute fibers.

\begin{tabular}{lccc}
\hline Lignins & $M_{w}(\mathrm{kDa})^{\mathrm{a}}$ & $M_{n}(\mathrm{kDa})^{\mathrm{b}}$ & $M_{w} / M_{n}{ }^{\mathrm{c}}$ \\
\hline Control jute & $46.662 \pm 1.756$ & $27.670 \pm 0.072$ & $1.69 \pm 0.07$ \\
Laccase-treated jute & $58.426 \pm 1.392$ & $33.721 \pm 1.537$ & $1.74 \pm 0.04$ \\
\hline
\end{tabular}

${ }^{a} t=11.950>t_{0.05 / 2.2}$ indicated significant difference for $M_{w}$.

${ }^{\mathrm{b}} t=5.567>t_{0.05 / 2.2}$ indicated significant difference for $M_{n}$.

${ }^{c} t=1.768>t_{0.05 / 2.2}$ indicated insignificant difference for $M_{w} / M_{n}$.

quantitative analysis, the weight-average molecular weight and number-average molecular weight of lignin isolated from laccase-treated jute fibers were 58,426 and 33,721, respectively, increasing by $25.2 \%$ and $21.9 \%$, respectively, compared with the control lignin. In addition, laccase-treated jute fiber lignin showed boarder molecular weight distribution, which embodied in the increase of polydispersity from 1.69 (control lignin) to 1.74. The similar outcome was also obtained by Zhou et al. (2013b) in studies on the structure characterization of sodium lignosulfonate by laccase modification. Although some lignins were degraded from the jute fibers by laccase, the result of the residual lignins on jute fibers was larger macromolecular scales and distribution. This is possibly attributed to the laccasemediated latter polymerization of lignins and cross-coupling by the dissolved phenolic fragments.

\section{Elemental analysis of lignins from Jute fibers}

The contents of carbon, hydrogen, oxygen, and methoxyl group as well as the $\mathrm{C}_{9}$ formulas of lignins were listed in Table 3. Lignin isolated from laccase-treated jute fibers had higher oxygen content and lower $\mathrm{C} / \mathrm{O}$ ratio, owing to the oxidation by laccase. Besides, the methoxyl content of lignin calculated from the ${ }^{1} \mathrm{H}-\mathrm{NMR}$ spectra was decreased, which suggested the demethylation of lignin was

Table 3. Element analysis, methoxyl group content, and $C_{9}$ formulas of lignins isolated from the control and laccase-treated jute fibers.

\begin{tabular}{lccccccc}
\hline & \multicolumn{3}{c}{ Elemental content (\%) $)^{\mathrm{a}}$} & & & \\
\cline { 2 - 4 } Lignins & $\mathrm{C}$ & $\mathrm{H}$ & $\mathrm{O}$ & & $\mathrm{C} / \mathrm{O}$ & $\mathrm{OCH}_{3}(\%)$ & $\mathrm{C}_{9}$ formulas \\
\hline Control jute & 56.37 & 5.65 & 37.98 & 1.48 & 18.21 & $\mathrm{C}_{9} \mathrm{H}_{44} \mathrm{O3}_{92}\left(\mathrm{OCH}_{3}\right)_{1.29}$ \\
Laccase-treated jute & 56.06 & 5.57 & 38.37 & 1.46 & 17.46 & $\mathrm{C}_{9} \mathrm{H}_{43} \mathrm{O4}_{02}\left(\mathrm{OCH}_{3}\right)_{1.23}$ \\
\hline
\end{tabular}

${ }^{a}$ Normally, the deviation of the elemental analyzeris lower than $0.1 \%$ for the elements CHNS. 
accompanied during the oxidation treatment of laccase. This result was compatible to earlier report of Sealey and Ragauskas (1998b). The methoxyl groups were demethylated to phenolic hydroxyl groups at first and then went through the oxidation and covalent crosslinking to form ether structures, which would result in the coupling between lignin units and polymerization of lignins.

\section{FT-IR Analysis of lignins from Jute fibers}

Figure 3 showed the FT-IR spectra of lignins isolated from control and laccase-treated jute fibers. The corresponding assignments of absorption peaks (Xu et al. 2006) and relative transmittances were given in Table 4. Relative transmittance of each peak was calculated with the transmittance of the aromatic skeletal vibration as the standard. As can be seen in Figure 2, the chemical structure of the control and laccase-treated lignins was similar. However, the contents of functional groups in lignins were various according to Table 4 . The broad peak at $3442 \mathrm{~cm}^{-1}$ was corresponding to the $\mathrm{O}-\mathrm{H}$ stretching vibration. The nonconjugated $\mathrm{C}=\mathrm{O}$ stretching vibration was observed at $1735 \mathrm{~cm}^{-1}$, and the aromatic skeletal vibration appeared at $1505 \mathrm{~cm}^{-1}$. The peak at $1422 \mathrm{~cm}^{-1}$ represented the aromatic skeletal vibration combined with the $\mathrm{C}-\mathrm{H}$ in-plane deformation in $-\mathrm{OCH}_{3}$. Compared with control lignin, the laccase-modified lignin showed higher relative transmittances in $\mathrm{O}-\mathrm{H}$ stretching vibration, $\mathrm{C}-\mathrm{H}$ in-plane deformation of $-\mathrm{OCH}_{3}$, and lower relative transmittance in nonconjugated $\mathrm{C}=\mathrm{O}$ stretching vibration. This is in accordance with the results reported by Sealey and Ragauskas (1998b) in residual lignin studies of laccase-delignified kraft pulps. These results supported the fact that phenolic hydroxyl groups in lignins were oxidized by laccase along with the demethylation of methoxyl groups and generation of new unconjugated carbonyl groups.

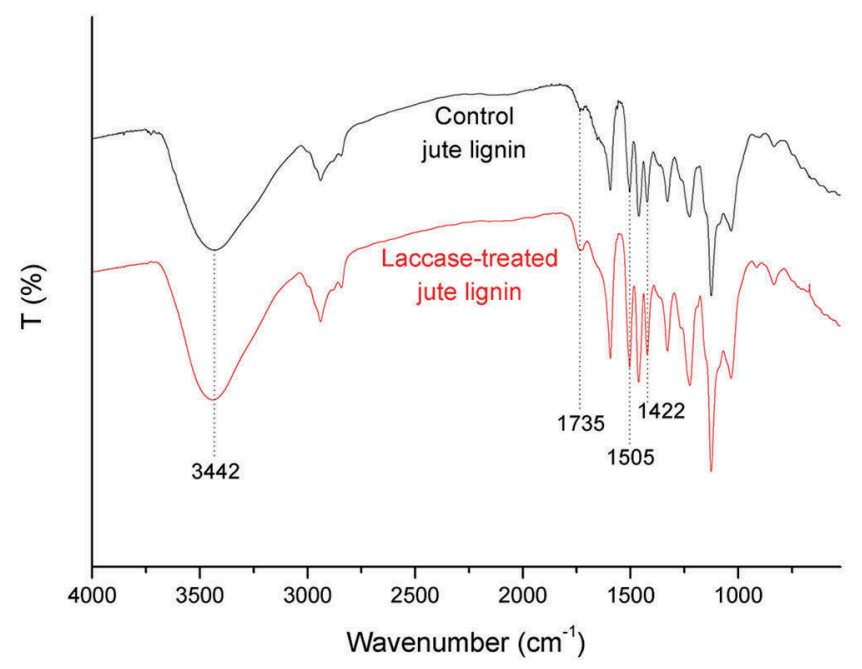

Figure 3. FT-IR spectra of lignins isolated from the control and laccase-treated jute fibers.

Table 4. Absorption peak assignments and relative transmittances in the FT-IR spectra of lignins isolated from the control and laccase-treated jute fibers.

\begin{tabular}{llcc} 
& & \multicolumn{2}{c}{ Relative transmittance } \\
\cline { 3 - 4 } Wavenumber $\left(\mathrm{cm}^{-1}\right)$ & \multicolumn{1}{c}{ Functional group assignment } & Control jute lignin & Laccase-treated jute lignin \\
\hline 3442 & $\mathrm{O}-\mathrm{H}$ stretching vibration & 0.91 & 0.95 \\
1735 & Nonconjugated $\mathrm{C}=\mathrm{O}$ stretching vibration & 1.19 & 1.13 \\
1505 & Aromatic skeletal vibration & 1.00 & 1.00 \\
1422 & Aromatic skeletal vibration combined with $\mathrm{C}-\mathrm{H}$ & 0.98 & 1.02 \\
& in-plane deformation in $-\mathrm{OCH}_{3}$ & & \\
\hline
\end{tabular}




\section{${ }^{1} H$-NMR analysis of lignins from Jute fibers}

The ${ }^{1} \mathrm{H}$-NMR spectra of the acetylated lignins isolated from control and laccase-treated jute fibers were shown in Figure 4. Table 5 listed the assignments of signals (Yan et al. 2009) and the corresponding numbers of protons per $\mathrm{C}_{9}$ structural unit. The numbers of phenolic and aliphatic hydroxyl groups per $\mathrm{C}_{9}$ unit in each lignin were calculated from the proton numbers of acetates in the ${ }^{1} \mathrm{H}$-NMR spectra and exhibited in Table 6. The number of phenolic hydroxyl groups in lignin was decreased from $0.19 / \mathrm{C} 9$ to $0.16 / \mathrm{C} 9$ after the laccase treatment, which is in accordance with the results in FT-IR analysis. However, the content of aliphatic hydroxyl groups remained almost the same, because the redox potential of laccases normally couldn't be high enough like horse radish peroxidases to oxidize the alcoholic hydroxyl groups. The similar change was observed by Zhou et al. (2013b) from the modification of sodium lignosulfonate by laccase.

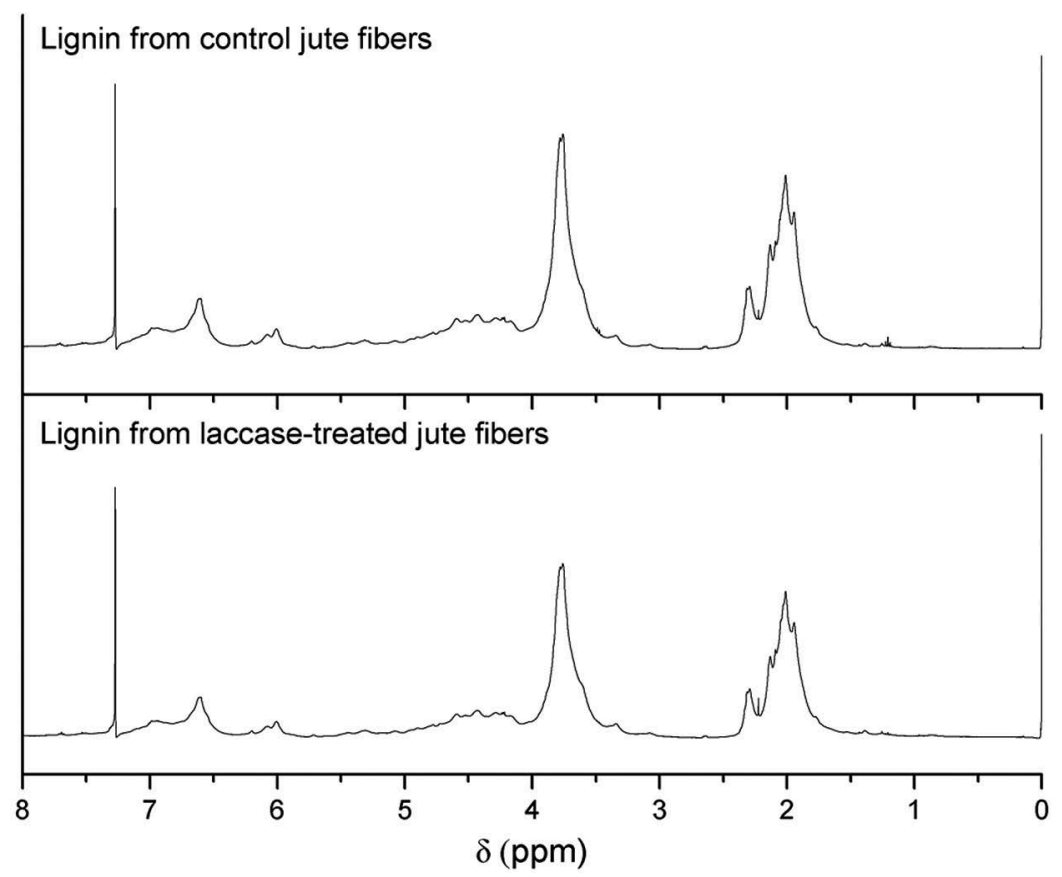

Figure 4. ${ }^{1} \mathrm{H}-\mathrm{NMR}$ spectra of acetylated lignins isolated from the control and laccase-treated jute fibers.

Table 5. Assignments of signals and numbers of protons per $\mathrm{C}_{9}$ structural unit in the ${ }^{1} \mathrm{H}-\mathrm{NMR}$ spectra of acetylated lignins isolated from the control and laccase-treated jute fibers.

\begin{tabular}{|c|c|c|c|}
\hline \multirow[b]{2}{*}{ Range (ppm) } & \multirow[b]{2}{*}{ Assignment } & \multicolumn{2}{|c|}{ Protons $/ C_{9}$} \\
\hline & & Control jute lignin & Laccase-treated jute lignin \\
\hline 7.27 & Chloroform (solvent) & & \\
\hline $7.25-6.80$ & Aromatic proton in guaiacyl units & 0.52 & 0.49 \\
\hline $6.80-6.25$ & Aromatic proton in syringyl units & 0.82 & 0.81 \\
\hline $6.25-5.75$ & $\mathrm{H}_{\alpha}$ of $\beta-0-4$ and $\beta-1$ structures & 0.25 & 0.26 \\
\hline $5.75-5.20$ & $\mathrm{H}_{a}$ of $\beta-5$ structure & 0.13 & 0.14 \\
\hline $5.20-4.90$ & $\mathrm{H}$ of xylan residue & 0.16 & 0.15 \\
\hline $4.90-4.30$ & $\mathrm{H}_{\alpha}$ and $\mathrm{H}_{\beta}$ of $\beta-0-4$ structure & 1.19 & 1.10 \\
\hline $4.30-4.00$ & $H_{\alpha}$ of $\beta-\beta$ structure, $H$ of xylan residue & 0.64 & 0.59 \\
\hline $4.00-3.48$ & $\mathrm{H}$ of methoxyl group & 3.86 & 3.71 \\
\hline $2.50-2.22$ & $\mathrm{H}$ of aromatic acetate & 0.56 & 0.48 \\
\hline $2.22-1.60$ & $\mathrm{H}$ of aliphatic acetate & 3.66 & 3.63 \\
\hline $1.60-1.30$ & $\mathrm{H}$ of hydrocarbon & 0.06 & 0.12 \\
\hline
\end{tabular}


Table 6. Numbers of hydroxyl groups per $C_{9}$ structural unit in lignins isolated from the control and laccase-treated jute fibers calculated by ${ }^{1} \mathrm{H}-\mathrm{NMR}$.

\begin{tabular}{lccc}
\hline & \multicolumn{3}{c}{ Numbers of hydroxyl groups/C } \\
\cline { 2 - 4 } Lignins & $\mathrm{OH}_{\text {phenolic }}$ & $\mathrm{OH}_{\text {aliphatic }}$ & $\mathrm{OH}_{\text {total }}$ \\
\hline Control jute & 0.19 & 1.22 & 1.41 \\
Laccase-treated jute & 0.16 & 1.21 & 1.37 \\
\hline
\end{tabular}

The connections between lignin structural units were also transformed after the laccase treatment. The proportions of aryl glycerol $\beta$-O- 4 aryl ether linkages and phenylcumarane $\beta$ - $\beta$ linkages in modified lignin were decreased, while more $\beta-5$ and $\beta-1$ structures were formed in response. It is most likely that the depolymerization of lignin at the early stage mainly occurred on the $\beta-\mathrm{O}-4$ and $\beta-\beta$ structures and that phenoxyl radicals in lignins generated by the laccase-mediated oxidation of phenolic hydroxyl groups were coupled at the latter stage with more $\beta-5$ and $\beta-1$ bonds.

\section{Distribution of lignin on Jute fiber surface}

Since lignin has strong autofluorescence in visible regions, the CLSM can be employed to observe themorphology of lignin distribution in lignocellulose materials (Sun et al. 2015a). The CLSM images of the jute fiber sections without and with autofluorescence of lignin were shown in Figures $5 \mathrm{a}$ and $5 \mathrm{~b}$, respectively. As can be seen in Figure 5a, the diameter of jute single fibers is generally 15-25 $\mu \mathrm{m}$ with an oval cavity inside. Jute technical fibers are rectangular and composed of 6-20 single fibers by parallel overlapping attached with intercellular substance including pectin, hemicellulose, and lignin (Mukhopadhyay et al. 1985). In Figure 5b, the fluorescence intensity of the middle lamella is obviously higher than that of the secondary cell wall, which indicated larger lignin concentration in middle lamella of jute fibers. Research showed that the lignin concentration in the middle lamella of lignocellulosic fibers is $60 \%-90 \%$ although the total proportion of lignin is only approximately $20 \%$ due to the low area of middle lamella contrasted with the secondary cell wall (Hearle and Peters 1963). As enzymatic treatments normally only occur on the fiber surface (mainly the middle lamella), this distribution of lignin has great advantages in the surface modification by ligninsubstrated laccases.

Figure 6 showed the SEM images of the control jute fiber surface and laccase-treated jute fiber surface. The control jute fiber surface was rough and irregular covered loosely with numbers of lamelleted impurities. As the surface of jute fibers is mainly composed of middle lamella and primary cell wall, these components are considered as the mixture of lignin, hemicellulose, and pectin (Baley et al. 2006). After the laccase treatment, the jute fiber surface became smooth and
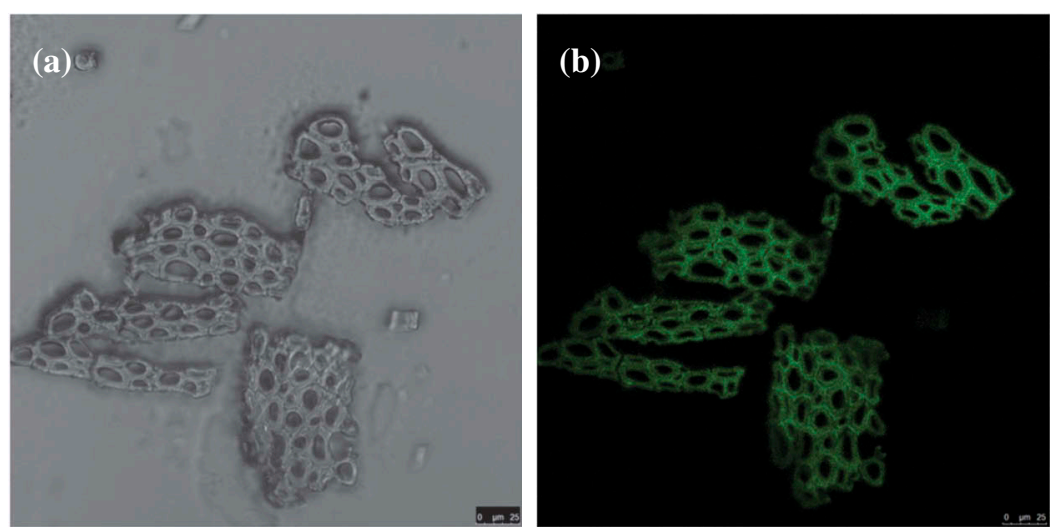

Figure 5. CLSM images of the jute fiber sections (a) without autofluorescence and (b) with autofluorescence of lignin. 

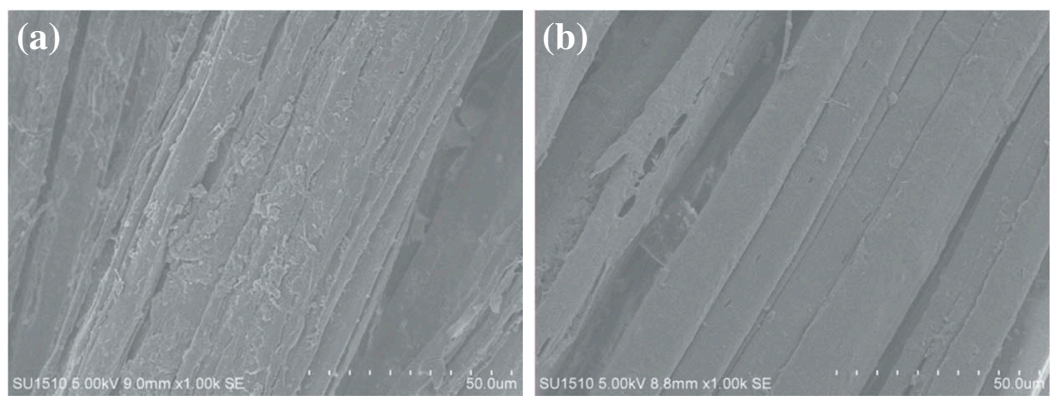

Figure 6. SEM images of the (a) control jute fiber surface and (b) laccase-treated jute fiber surface.

neat with lignin, etc. attached tightly. This is possibly because of the enzymatic dislodgement and redistribution of the bulgy lignins on the jute surface. The degradation and subsequent polymerization of lignin by laccase discussed above could redistribute lignins on the jute surface and made the jute surface glossy.

\section{Conclusions}

This work presented the changes of lignin in jute fibers in terms of content, structure, and surface distribution after the laccase treatment. Four percent lignin was removed from the jute fibers by laccase. At first, some lignins were degraded and dissolved in the aqueous medium. However, part of the dissolved lignin fragments could couple back to the lignin macromolecules on jute fibers at the latter stage of the laccase catalysis. Because of the laccase-mediated polymerization of lignin and cross-coupling with lignin fragments, the molecular weights of the residue lignins in the laccasetreated jute fibers were increased. Besides, the phenolic hydroxyl, methoxyl, $\beta-\mathrm{O}-4$, and $\beta-\beta$ contents in lignins isolated from the laccase-treated jute fibers were decreased, while the contents of carbonyl groups, $\beta-5$ and $\beta-1$ linkages were increased in response. This indicated that the phenolic hydroxyl groups in lignins were oxidized by laccase to phenoxyl radicals and then cross-coupled to form more carbon bonds rather than ether linkages. Meanwhile, the demethylation of methoxyl groups and generation of new unconjugated carbonyl groups were accompanied. Due to the degradation and subsequent polymerization of lignin by laccase, the bulgy lignins on the jute fiber surface were redistributed, which made the surface neat and glossy. The conclusions in this article provided useful references to reveal the lignin transformation during the laccase treatment of jute fibers, which would be beneficial for the scouring, bleaching, resistance toward microbial attack, or hydrophobic modification of jute textiles.

\section{Funding}

This work was financially supported by the National Natural Science Foundations of China $(51603087,51673087)$, Program for Changjiang Scholars and Innovative Research Team in University (IRT_15R26), Fundamental Research Funds for the Central Universities (JUSRP51717A), Key R\&D Program of Jiangsu Province (BE2016208), Portuguese Foundation for Science and Technology (UID/BIO/04469/2013 unit), and COMPETE 2020 (POCI-01-0145-FEDER006684).

\section{References}

Abdullah, A., K. K. Magniez, and B. L. Fox. 2011. A surface-property relationship of atmospheric plasma treated jute composites. Composites Science and Technology 71: 1692-1698. doi:10.1016/j.compscitech.2011.07.011.

Adler, E. 1957. Structural elements of lignin. Industrial \& Engineering Chemistry 49: 1377-1383. doi:10.1021/ie50573a031. 
Alves, A., M. Schwanninger, H. Pereira, and J. Rodrigues. 2006. Analytical pyrolysis as a direct method to determine the lignin content in wood: Part 1: Comparison of pyrolysis lignin with Klason lignin. Journal of Analytical and Applied Pyrolysis 76: 209-213. doi:10.1016/j.jaap.2005.11.004.

Areskogh, D., J. Li, G. Gellerstedt, and G. Henriksson. 2010. Investigation of the molecular weight increase of commercial lignosulfonates by laccase catalysis. Biomacromolecules 11: 904-910. doi:10.1021/bm901258v.

Baley, C., F. Busnel, Y. Grohens, and O. Sire. 2006. Influence of chemical treatments on surface properties and adhesion of flax fibre-polyester resin. Composites Part A: Applied Science and Manufacturing 37: $1626-1637$. doi:10.1016/j.compositesa.2005.10.014.

Cao, X., B. Ding, J. Yu, and S. S. Al-Deyab. 2012. Cellulose nanowhiskers extracted from TEMPO-oxidized jute fibers. Carbohydrate Polymers 90: 1075-1080. doi:10.1016/j.carbpol.2012.06.046.

Childs, R., and W. Bardsley. 1975. The steady-state kinetics of peroxidase with 2,2'-azino-bis-(3-ethylthiazoline-6-sulfonic acid) as chromogen. Biochemistry Journal 145: 93-103. doi:10.1042/bj1450093.

Datta, U. 2007. Application of jute geotextiles. Journal of Natural Fibers 4: 67-82. doi:10.1300/J395v04n03_05.

Del Río, J. C., J. Rencoret, G. Marques, J. Li, G. Gellerstedt, J. Jimenez-Barbero, A. T. Martínez, and A. Gutierrez. 2009. Structural characterization of the lignin from jute (Corchorus capsularis) fibers. Journal of Agricultural and Food Chemistry 57: 10271-10281. doi:10.1021/jf900815x.

Ghosh, M., D. Biswas, and P. Sanyal. 2016. Development of jute braided sapling bag for nursery use. Journal of Natural Fibers 13: 146-157. doi:10.1080/15440478.2014.1002147.

Hearle, J. W. S., and R. H. Peters. 1963. Fiber structure. Manchester, UK: The Textile Institute.

Hüttermann, A., C. Mai, and A. Kharazipour. 2001. Modification of lignin for the production of new compounded materials. Applied Microbiology and Biotechnology 55: 387-394. doi:10.1007/s002530000590.

Jahan, M. S., and S. P. Mun. 2010. Isolation and characterization of lignin from tropical and temperate hardwood. Bangladesh Journal of Scientific and Industrial Research 44: 271-280. doi:10.3329/bjsir.v44i3.4399.

Jahan, M. S., and S. Rawshan. 2009. Reinforcing potential of jute pulp with trema orientalis (nalita) pulp. Bioresources 4: 921-931.

Liu, N., S. Shi, Y. Gao, and M. Qin. 2009. Fiber modification of kraft pulp with laccase in presence of methyl syringate. Enzyme and Microbial Technology 44: 89-95. doi:10.1016/j.enzmictec.2008.10.014.

Lundquist, K., B. Ohlsson, and R. Simonson. 1977. Isolation of lignin by means of liquid-liquid extraction. Svensk Papperstidning 80: 143-144.

Mattinen, M. L., T. Suortti, R. Gosselink, D. S. Argyropoulos, D. Evtuguin, A. Suurnäkki, E. Jong, and T. Tamminen. 2008. Polymerization of different lignins by laccase. Bioresources 3: 549-565.

Mukhopadhyay, A. K., S. K. Bandyopadhyay, and U. Mukhopadhyay. 1985. Jute fibers under scanning electron microscopy. Textile Research Journal 55: 733-737. doi:10.1177/004051758505501204.

Mwaikambo, L. Y. 2006. Review of the history, properties and application of plant fibres. African Journal of Science and Technology 7: 120-133.

Nyanhongo, G. S., T. Kudanga, E. N. Prasetyo, and G. M. Guebitz. 2011. Enzymatic polymer functionalisation: Advances in laccase and peroxidase derived lignocellulose functional polymers. Advances in Biochemical Engineering/Biotechnology 125: 47-68.

Pepper, J. M., P. E. T. Baylis, and E. Adler. 1959. The isolation and properties of lignins obtained by the acidolysis of spruce and aspen woods in dioxane-water medium. Canadian Journal of Chemistry 37: 1241-1248. doi:10.1139/v59-183.

Riva, S. 2006. Laccases: Blue enzymes for green chemistry. Trends in Biotechnology 24: 219-226. doi:10.1016/j. tibtech.2006.03.006.

Sealey, J., and A. J. Ragauskas. 1998a. Investigation of laccase/N-hydroxybenzotriazole delignification of kraft pulp. Journal of Wood Chemistry and Technology 18: 403-416. doi:10.1080/02773819809349588.

Sealey, J., and A. J. Ragauskas. 1998b. Residual lignin studies of laccase-delignified kraft pulps. Enzyme and Microbial Technology 23: 422-426. doi:10.1016/S0141-0229(98)00056-8.

Sirghie, C., M. Dochia, I. V. Istoc, D. Chambre, and L. Copolovici. 2015. A comparison of a new method mediated by molybdenum complex with an enzymatic method for bleaching flax fibers. Journal of Natural Fibers 12: 378-387. doi:10.1080/15440478.2014.929557.

Sun, F. F., L. Wang, J. Hong, J. Ren, F. Du, J. Hu, Z. Zhang, and B. Zhou. 2015a. The impact of glycerol organosolv pretreatment on the chemistry and enzymatic hydrolyzability of wheat straw. Bioresource Technology 187: $354-361$. doi:10.1016/j.biortech.2015.03.051.

Sun, S., T. Xing, and R. Tang. 2015b. Enzymatic dyeing and functional finishing of textile fibres with ferulic acid. Indian Journal of Fibre \& Textile Research 40: 62-69.

Thakur, K., S. Kalia, B. S. Kaith, D. Pathania, and A. Kumar. 2015. Surface functionalization of coconut fibers by enzymatic biografting of syringaldehyde for the development of biocomposites. RSC Advances 5: 76844-76851. doi:10.1039/C5RA14891J.

Wong, D. W. 2009. Structure and action mechanism of ligninolytic enzymes. Applied Biochemistry and Biotechnology 157: 174-209. doi:10.1007/s12010-008-8279-z.

$\mathrm{Xu}$, Q., M. Qin, S. Shi, L. Jin, and Y. Fu. 2006. Structural changes in lignin during the deinking of old newsprint with laccase-violuric acid system. Enzyme and Microbial Technology 39: 969-975. doi:10.1016/j.enzmictec.2006.01.031. 
Yan, T., Y. Xu, and C. Yu. 2009. The isolation and characterization of lignin of kenaf fiber. Journal of Applied Polymer Science 114: 1896-1901. doi:10.1002/app.v114:3.

Zhou, H., D. Yang, X. Qiu, X. Wu, and Y. Li. 2013a. A novel and efficient polymerization of lignosulfonates by horseradish peroxidase $/ \mathrm{H}_{2} \mathrm{O} 2$ incubation. Applied Microbiology and Biotechnology 97: 10309-10320. doi:10.1007/ s00253-013-5267-1.

Zhou, H., D. Yang, X. Wu, and X. Qiu. 2013b. Structure and adsorption characterization of sodium lignosulfonate by laccase modification. Chemical Journal of Chinese Universities 34: 218-224. 